Research Article

\title{
Hidden heterochromatin: Characterization in the Rodentia species Cricetus cricetus, Peromyscus eremicus (Cricetidae) and Praomys tullbergi (Muridae)
}

\author{
Ana Paço, Filomena Adega, Henrique Guedes-Pinto and Raquel Chaves \\ Institute for Biotechnology and Bioengineering, Centre of Genetics and Biotechnology, \\ University of Trás-os-Montes and Alto Douro, Vila Real, Portugal.
}

\begin{abstract}
The use of in situ restriction endonuclease (RE) (which cleaves DNA at specific sequences) digestion has proven to be a useful technique in improving the dissection of constitutive heterochromatin $(\mathrm{CH})$, and in the understanding of the $\mathrm{CH}$ evolution in different genomes. In the present work we describe in detail the $\mathrm{CH}$ of the three Rodentia species, Cricetus cricetus, Peromyscus eremicus (family Cricetidae) and Praomys tullbergi (family Muridae) using a panel of seven REs followed by $\mathrm{C}$-banding. Comparison of the amount, distribution and molecular nature of C-positive heterochromatin revealed molecular heterogeneity in the heterochromatin of the three species. The large number of subclasses of $\mathrm{CH}$ identified in Praomys tullbergi chromosomes indicated that the karyotype of this species is the more derived when compared with the other two genomes analyzed, probably originated by a great number of complex chromosomal rearrangements. The high level of sequence heterogeneity identified in the $\mathrm{CH}$ of the three genomes suggests the coexistence of different satellite DNA families, or variants of these families in these genomes.
\end{abstract}

Key words: constitutive heterochromatin, in situ restriction endonuclease digestion, Rodentia.

Received: April 14, 2008; Accepted: July 14, 2008.

\section{Introduction}

Constitutive heterochromatin $(\mathrm{CH})$ is a ubiquitous and abundant component of eukaryotic genomes that accounts for $\sim 30 \%$ of the genome in humans and up to $50 \%$ in the kangaroo rat (Dipidomys ordii) (Singer, 1982; Dimitri et al., 2004, 2005; Rossi et al., 2007). The similarity in the genetic and molecular properties of $\mathrm{CH}$ among plants and animals, led to the traditional view of this genome fraction as a "genomic wasteland" or a repository of "junk" DNA (John, 1988). Nowadays this idea is becoming obsolete; in fact, in the past two decades molecular genetics studies have implicated $\mathrm{CH}$ in important cellular functions, in a remarkable structural and functional basis (Dimitri et al., 2004, 2005; Corradini et al., 2007; Rossi et al., 2007).

Constitutive heterochromatin can occur as large blocks or discrete C-positive bands in any part of a chromosome, but is most commonly found in large blocks near the centromere (Corradini et al., 2007; Probst and Almouzni, 2008). Satellite DNA, the main constituent of this genomic fraction, usually occurs in the centromeric region of chromosomes (Chaves et al., 2000), but is also frequently found at telomeres (Shore, 2001). The occurrence of $\mathrm{CH}$ at interstitial positions is much less common, although large

Send correspondence to Raquel Chaves. Institute for Biotechnology and Bioengineering, Centre of Genetics and Biotechnology, University of Trás-os-Montes and Alto Douro, Vila Real, Portugal. E-mail: rchaves@utad.pt. blocks of interstitial $\mathrm{CH}$ have been found in the large chromosomes of some insects (John et al., 1985), plants (Bauchan and Hossain, 1999) and some mammals (Santos et al., 2004; Adega et al., 2007; Meles et al., 2008).

Although present in almost all eukaryotes, the sequence and chromosomal organization of $\mathrm{CH}$ is not well conserved among species. Indeed, there is strong evidence for the sharing of homologous satellite DNA sequences by closely related species (Waye and Willard, 1989; Jobse et al., 1995; Lee et al., 1999; Saito et al., 2007), with species-specific sequences of satellite DNA occurring in almost all taxonomic groups (Slamovits and Rossi, 2002).

It seems reasonable to accept that the presence of $\mathrm{CH}$ facilitates the occurrence of chromosome rearrangements, as it is in accordance with several authors that consider $\mathrm{CH}$ as hotspots for structural chromosome rearrangements (Yunis and Yasmineh 1971; Peacock et al., 1982; John, 1988; Chaves et al., 2004b). Wichman et al. (1991) postulated that rapidly evolving families or variants of satellite DNA can promote chromosomal rearrangements via of their intragenomic movements among non-homologous chromosomes and between different chromosomal regions such as centromeres, arms and telomeres.

Sequences of $\mathrm{CH}$ can be easily detected by the preferential "loss" of DNA from non-C-band regions of chromosomes (Comings, 1973; Pathak and Arrighi, 1973), achieved by conventional C-banding, involving depu- 
rination and denaturation of chromosomal DNA (Arrighi and Hsu, 1971; Sumner, 1972) followed by its extraction during incubation in a saline solution (Holmquist and Dancis, 1979; Verma and Babu, 1995). Nevertheless other analytical methodologies are indispensable when a detailed molecular characterization of $\mathrm{CH}$ is the central issue. The use of in situ restriction endonuclease (RE) digestion proved to be a very useful technique in improving the dissection of $\mathrm{CH}$, and in the understanding of the $\mathrm{CH}$ evolution in different genomes (Gosálvez et al., 1997; Pieczarka et al., 1998). Besides the ability of REs followed by Cbanding in demonstrating the $\mathrm{C}$-heterochromatin heterogeneity (Rocco et al., 2002; Schmid et al., 2002; Chaves et al., 2004b; Adega et al., 2005).

In this work, we used seven restriction endonucleases followed by C-banding to study the heterochromatin of three Rodentia species, Cricetus cricetus, Peromyscus eremicus (family Cricetidae) and Praomys tullbergi (family Muridae). In rodents' chromosomes, in situ REs digestion was only applied without sequential C-banding and only in Microtus savii (Galleni et al., 1992), species from the genus Reithrodontomys (Van Den Bussche et al., 1993) (family Muridae) and from the genus Ctenomys (family Octodontidae) (García et al., 2000a, 2000b). The approach used here allowed a detailed $\mathrm{CH}$ characterization in terms of its location, detection of different $\mathrm{CH}$ subclasses, and revelation of its molecular composition.

\section{Materials and Methods}

\section{Chromosome preparations}

The material analyzed consisted of chromosomal preparations of Cricetus cricetus (CCR), Peromyscus eremicus (PER) and Praomys tullbergi (PTU), prepared from fibroblast cell lines obtained from the cell and tissue collection maintained at the Department of Systematics and Evolution, Muséum National d'Histoire Naturelle (MNHN), Paris. Standard cell culture was followed as described elsewhere (Chaves et al., 2004a) in order to prepare fixed chromosome spreads.

\section{GTD-banding}

Air dried slides were aged at $65^{\circ} \mathrm{C}$ for $5 \mathrm{~h}$ or overnight and then subjected to standard G-banding procedures with trypsin (Seabright, 1971). The same slides were subsequently fixed with formaldehyde and used for C-banding (Chaves et al., 2002). Slides were stained with DAPI for a better contrast. The inversion of the DAPI color in Adobe Photoshop (version 7.0) revealed the chromosomes G-banding pattern (GTD-banding, G-bands by trypsin with DAPI).

\section{In situ $\mathrm{RE}$ digestion}

Air dried slides were aged at $65^{\circ} \mathrm{C}$ for $6 \mathrm{~h}$ and then submitted to in situ restriction enzyme (RE) digestion. The seven restriction enzymes used (AluI, ApaI, BamHI, DraI, HaeIII, PstI and RsaI) were diluted in buffers indicated by the manufacturer (Invitrogen Life Technologies) to give final concentrations of $30 \mathrm{U}$ per $100 \mu \mathrm{L}$ of solution. One hundred microliters of the desired solution was placed on slides that were then covered with coverslips and incubated in a moist chamber for $16 \mathrm{~h}$ at $37^{\circ} \mathrm{C}$. Control slides were incubated only with buffer under the same conditions. Prior to C-banding, the slides were fixed with formaldehyde. Finally, the slides were stained with DAPI (the inversion of the DAPI color revealed the RE-banding). The residual bands obtained after the endonuclease digestion were suitable for chromosome identification and karyotype organization.

\section{CBP-banding sequential to G-bands or RE-bands}

The C-banding technique was performed sequentially to G-bands or to RE banding and was carried out after distaining the slides. CBP-banding (ㄷ-bands by barium hydroxide using propidium iodide) was done using the standard procedure of Sumner (1972), but with propidium iodide as counterstain. The results presented below are representative of at least 35 metaphases from at least five independent experiments done for each endonuclease.

\section{Chromosome observation}

Chromosomes were observed with a Zeiss Axioplan 2 imaging microscope coupled to an Axiocam digital camera with AxioVision software (version Rel. 4.5). Digitized photos were prepared for printing in Adobe Photoshop (version 7.0); contrast and color optimization were the functions used and affected the whole of the image equally.

\section{Results and Discussion}

The karyotype of Cricetus cricetus has 22 chromosomes, being the first description performed by Matthey (1952). This karyotype is composed by five meta/submetacentric chromosome pairs, four submetacentric and one acrocentric, being the $\mathrm{X}$ chromosome a large meta/submetacentric. The karyotype of Peromyscus eremicus has 48 chromosomes, in agreement with the initial description by Hsu and Arrighi (1966). In this species, all of the chromosomes are submetacentric, being the $\mathrm{X}$ chromosome a large submetacentric and the $\mathrm{Y}$ a small submetacentric. The karyotype of Praomys tullbergi has 34 chromosomes in which all of the autosomes are acrocentric, the Y chromosome is a small acrocentric and the $\mathrm{X}$ chromosome is a large submetacentric (Matthey, 1958; Qumsiyeh et al., 1990; Capanna et al., 1996; Meles et al., 2008). The first description of this karyotype was reported by Matthey (1958).

The action of all seven different REs and REs $+\mathrm{C}$ banding on Cricetus cricetus, Peromyscus eremicus and Praomys tullbergi chromosomes are presented in Figures 1, 
2 and 3, respectively. The residual bands seen after digestion with endonucleases AluI, ApaI, BamHI, DraI, HaeIII, PstI and RsaI (left column for each enzyme shown in Figures 1-3) are mainly G-like and suitable for chromosome identification. Although each restriction endonuclease was expected to yield a specific banding pattern, in practice most of the banding patterns overlapped. Nevertheless some endonucleases (e.g. ApaI, PstI and RsaI in chromosomes of Cricetus cricetus, BamHI, PstI and RsaI in Peromyscus eremicus and HaeIII, PstI and RsaI in Praomys tullbergi) produced a higher banding contrast. AluI was, perhaps, the used enzyme that produced the smallest number of bands but the higher contrast banding pattern. It is important to refer that the banding patterns produced by each RE are reproducible and can be used in sequential experiment procedures without loss of chromosome morphology (Chaves et al., 2002; Adega et al., 2005).

In a general overview, the C-positive heterochromatin (Figures 1-3, right chromosome in each column, showing control C-banding and $\mathrm{RE}+\mathrm{C}$-banding) is mainly found at the centromeres of most chromosomes, although some C-bands can also be seen at interstitial and telomeric locations. In the individuals analyzed, some heterochromatin polymorphism of minor significance were detected, i.e., variation in the banding patterns of homologous chromosomes of the same pair, as also reported for pig (Adega et al., 2005) and some Tayassuidae species (Adega et al., 2007) chromosomes. The heterochromatin polymorphisms detected in the chromosomes of the studied species were not considered for the analysis relatively to the characterization of $\mathrm{CH}$ here presented, because they might not be representative of the population.

At least three major classes of $\mathrm{CH}$ were identified in the species studied in this work: (peri)centromeric, interstitial and telomeric (Figures 1-3). With $\mathrm{RE}+\mathrm{C}$-banding treatment, these major $\mathrm{C}$-positive heterochromatin blocks could be discriminated in at least $26 \mathrm{C}$-positive heterochromatin subclasses in the autosomal complement of Cricetus cricetus [seven in (peri)centromeric regions, 13 in interstitial regions and six in telomeric regions] and three $\mathrm{C}$ positive heterochromatin subclasses in the CCRX chromosome [one (peri)centromeric and two in interstitial regions] (cf. Figure 1). In Peromyscus eremicus chromosomes (Figure 2), the $\mathrm{RE}+\mathrm{C}$-banding treatment discriminated at least $26 \mathrm{C}$-positive heterochromatin subclasses in the autosomal complement [seven in (peri)centromeric regions, 13 in interstitial regions and six in telomeric regions], three $\mathrm{C}$ positive heterochromatin subclasses in the PERX chromosome (one in the centromeric region and two in interstitial regions) and two in the PERY chromosome (one centromeric and one subtelomeric). Finally, in Praomys tullbergi, the $\mathrm{RE}+\mathrm{C}$-banding treatment (Figure 3) discriminated the major C-positive heterochromatin blocks into at least 45 C-positive heterochromatin subclasses in the autosomal complement (two in centromeric regions, 35 in interstitial regions and eight in telomeric regions), four C-positive heterochromatin subclasses in the PTUX chromosome (one in the centromeric region and three in interstitial regions) and three in the PTUY chromosome (one in the centromeric region and two in interstitial regions).

\section{Constitutive Heterochromatin (C-positive heterochromatin) characterization in Cricetus cricetus}

Control experiment $(\mathrm{G}+\mathrm{C}$-banding) show that all the chromosomes of Cricetus cricetus exhibit large (peri)centromeric $\mathrm{C}$-bands that in most cases consist of two blocks of $\mathrm{CH}$ (exception goes to CCR7, CCR8 and CCR10 chromosomes which show only one block of $\mathrm{CH}$ ). Notice the very large centromeric $\mathrm{CH}$ block of the only acrocentric chromosome of the karyotype, CCR7. All the chromosomes except CCR3, CCR8 and CCR10 exhibit interstitial C-positive heterochromatin. Telomeric C-bands can be seen on chromosomes CCR1, CCR3, CCR5, CCR6, and CCR9.

Incubation of this species chromosomes with restriction endonucleases followed by $\mathrm{C}$-banding revealed $\mathrm{C}$ bands heterogeneity (Figure 1), being verified that (peri)centromeric, interstitial or telomeric C-bands present a different molecular nature, exhibiting different restriction patterns when submitted to the same panel of REs. This is not surprising as similar results have been reported for other species (Babu, 1988; Fernández-García et al., 1998; Chaves et al., 2004b; Adega et al., 2005, 2007).

The arrowheads in Figure 1 indicate C-bands revealed only after RE treatment (cryptic C-bands). Of the endonucleases used here, $\mathrm{BamHI}+\mathrm{C}$-banding was the one that produced the most evident effect in $\mathrm{CH}$ sequences of the Cricetus cricetus chromosomes. See for instance chromosomes CCR7, CCR8, CCR9 and CCR10, being observed less intense bands in comparison with the control chromosomes. This enzyme, along with ApaI $+\mathrm{C}$-banding and $\mathrm{RsaI}+\mathrm{C}$-banding, produced the partition of the (peri)centromeric $\mathrm{CH}$ band at chromosomes $\mathrm{CCR} 7$ and CCR10 into two distinct $\mathrm{CH}$ blocks, thus revealing the occurrence of two instead of one (peri)centromeric $\mathrm{CH}$ block [bands identified with an asterisk in Figure 1]. Some enzymes seem to have a drastic effect resulting in a more accentuated contrast pattern in the (peri)centromeric regions of some chromosomes. See, for example, chromosomes CCR1 and CCR6 with DraI+C-banding, CCR5 with BamHI + C-banding, CCR9 with BamHI + C-banding and DraI + C-banding.

\section{Constitutive heterochromatin (C-positive heterochromatin) characterization in Peromyscus eremicus}

In the control experiment ( $\mathrm{G}+\mathrm{C}$-banding) the majority of Peromyscus eremicus chromosomes exhibit large (peri)centromeric C-bands (Figure 2, left column), and in 
some of these chromosomes, the C-banding spreads from the centromeric region to the $\mathrm{p}$ arm telomere, apparently covering all the $\mathrm{p}$ arm, e.g., chromosomes PER9 and
PER17. In some chromosomes, this band seems to be split in two C-bands, one clearly centromeric and the other cov-

ering the chromosome $\mathrm{p}$ arm (chromosomes PER2, PER3

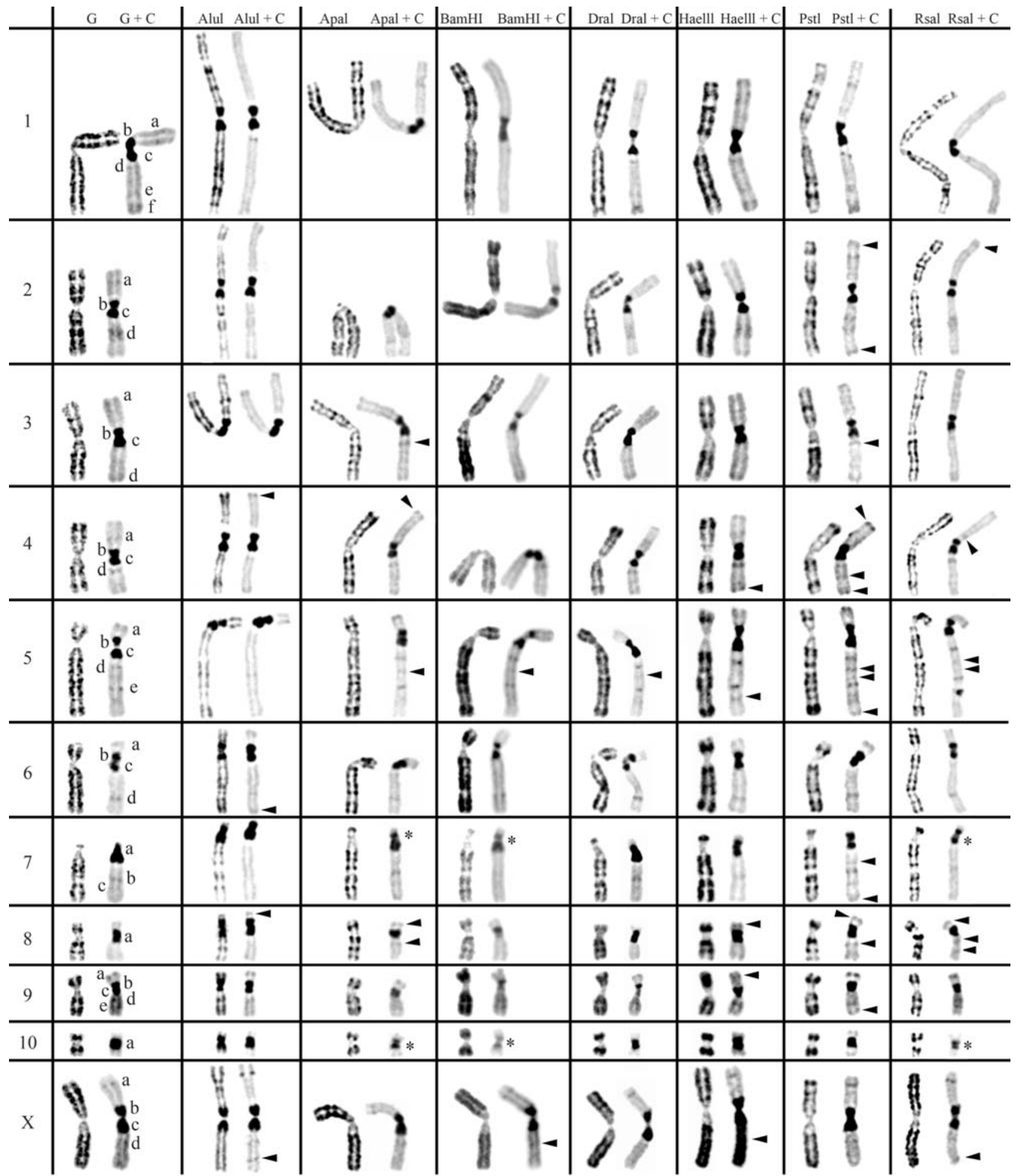

Figure 1 - Table resume of in situ restriction endonuclease digestion of Cricetus cricetus chromosomes $(2 n=22)$ and sequential C-banding. Control Gand C-banding of Cricetus cricetus chromosomes are shown on the left column. The other columns show the bands produced by the seven restriction endonucleases before and after C-banding. The letters (a-f) represent the C-bands according to their order of appearance in each chromosome. Arrowheads indicate $\mathrm{C}$-positive heterochromatin bands only revealed by previous RE treatment. Asterisks indicate extra C-bands produced by the splitting of a control C- band after endonuclease digestion+C-banding. 
and PER4). Chromosomes PER11 and PER16 display two well-defined bands of (peri)centromeric $\mathrm{CH}$, although this may have been an artifact caused by the small size of the $\mathrm{p}$ arms. Chromosomes PER1 and PERY apparently display the lowest amount of heterochromatin in control $\mathrm{G}+\mathrm{C}$ banding, showing PER1 only a small centromeric $\mathrm{CH}$ band.

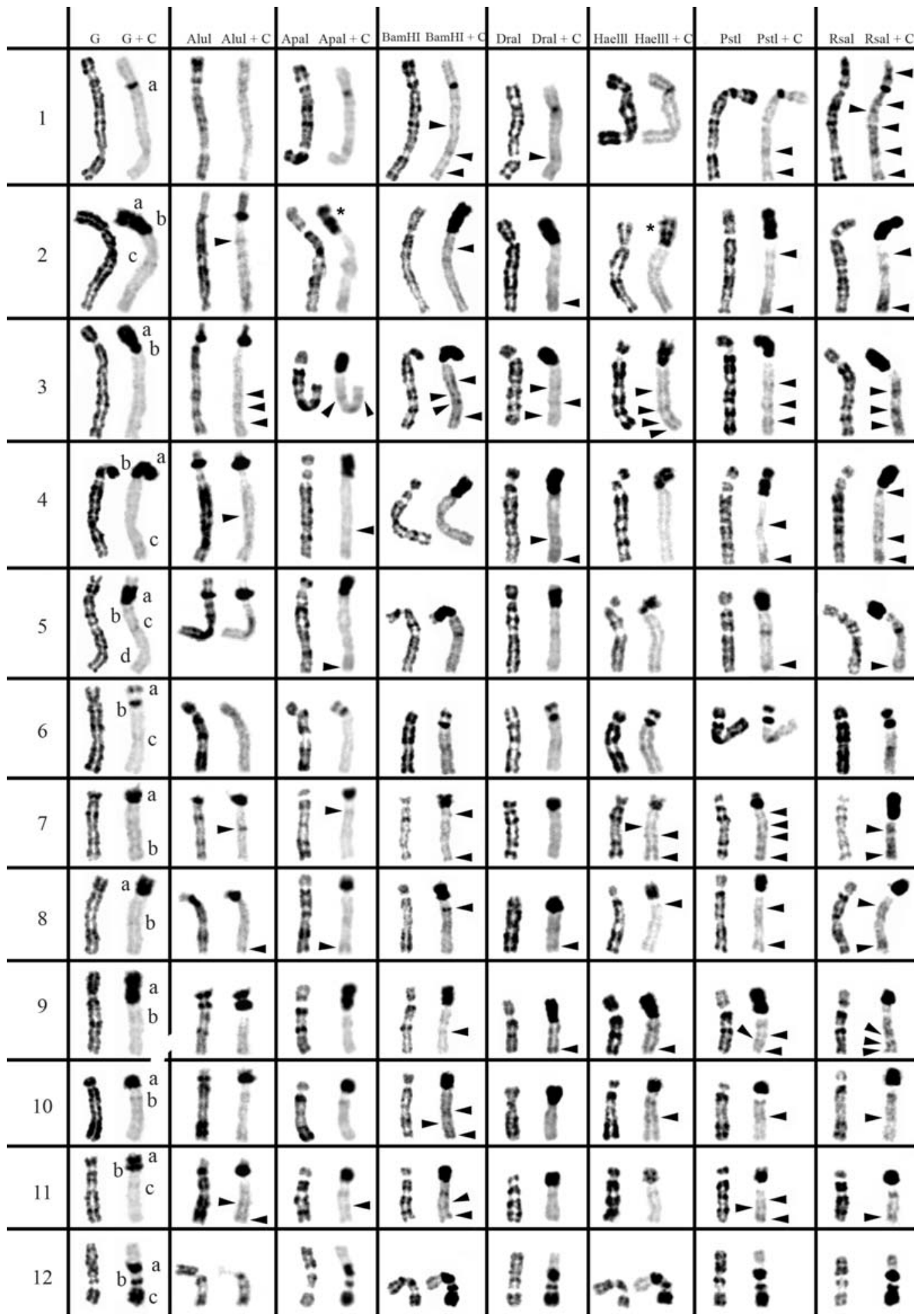

Figure 2 - Table resume of $i n$ situ restriction endonuclease digestion of Peromyscus eremicus chromosomes $(2 \mathrm{n}=48)$ and sequential C-banding. Control G- and C-banding of Peromyscus eremicus chromosomes are shown on the left column. The other columns show the bands produced by the seven restriction endonucleases, before and after C-banding. The letters (a-g) represent the C-bands according to their order of appearance in each chromosome. Arrowheads indicate $\mathrm{C}$-positive heterochromatin bands only revealed by previous $\mathrm{RE}$ treatment. Asterisks indicate extra C-bands produced by the splitting of a control C- band after endonuclease digestion+C-banding. 


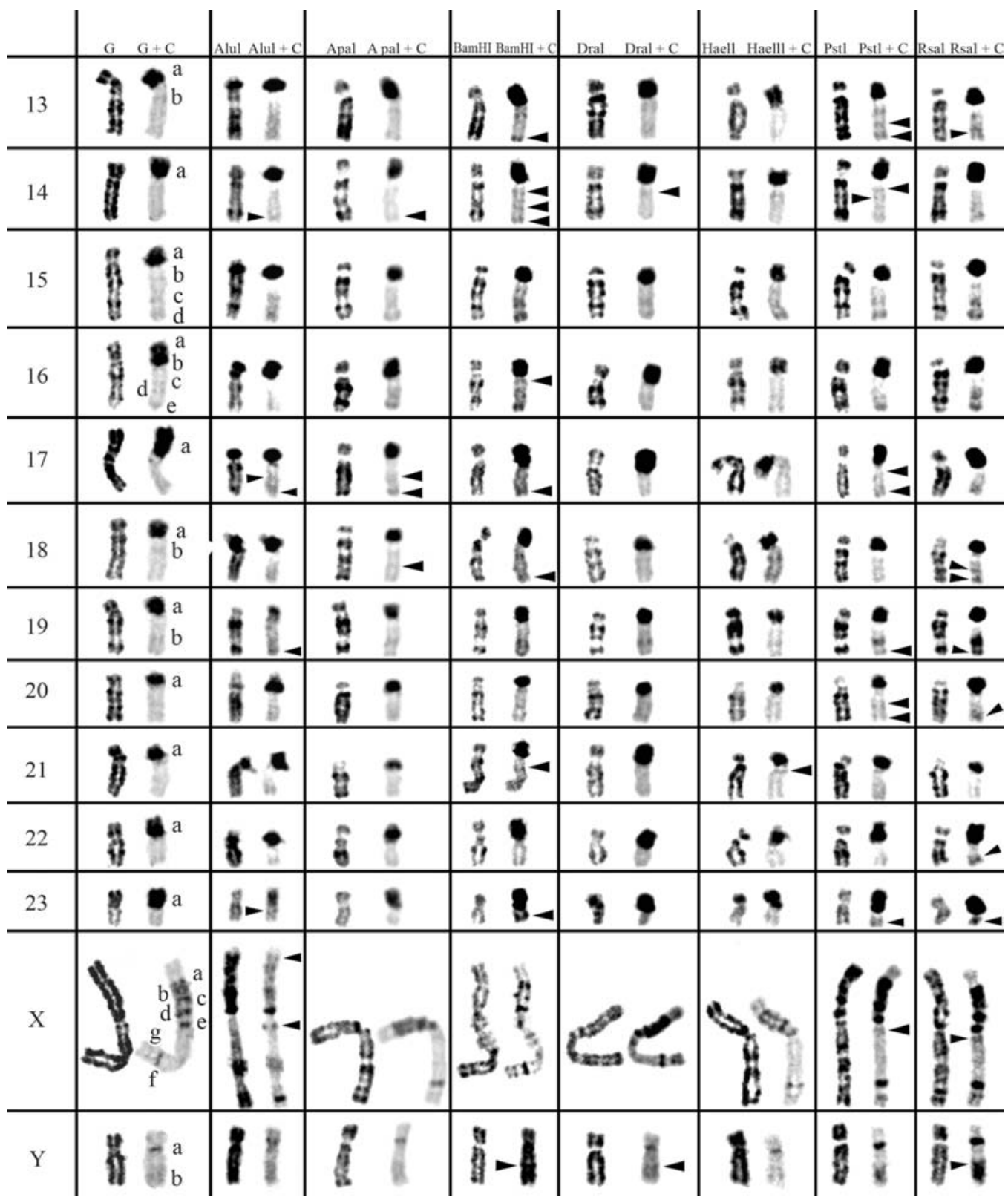

Figure 2 (cont.) - Table resume of in situ restriction endonuclease digestion of Peromyscus eremicus chromosomes $(2 \mathrm{n}=48)$ and sequential C-banding. Control G- and C-banding of Peromyscus eremicus chromosomes are shown on the left column. The other columns show the bands produced by the seven restriction endonucleases, before and after C-banding. The letters (a-g) represent the C-bands according to their order of appearance in each chromosome. Arrowheads indicate C-positive heterochromatin bands only revealed by previous RE treatment. Asterisks indicate extra C-bands produced by the splitting of a control C- band after endonuclease digestion+C-banding.

The situation observed in the PERY is not usual for most of the mammals' species, once this chromosome is usually the more heterochromatic of the whole complement. Some of the chromosomes exhibit C-bands at interstitial locations, presenting chromosome PERX the highest number of these bands (at least six). Telomeric C-bands can be observed in some chromosomes of this species, e.g., PER6, PER11, PER12, PER15 and PER16 (Figure 2).

When C-banding was applied after in situ REs digestion to the chromosomes of this species, it was possible to verify that its $\mathrm{CH}$ shows some degrees of heterogeneity
(Figure 2). The arrowheads in Figure 2 indicate C-bands revealed only after treatment with endonucleases (cryptic $\mathrm{C}$-bands). From the REs used in this work, $\mathrm{RsaI}+\mathrm{C}$ banding, PstI $+\mathrm{C}$-banding and $\mathrm{BamHI}+\mathrm{C}$-banding, were the enzymes that revealed the greatest number of $\mathrm{CH}$ bands not previously detected by the control $\mathrm{G}+\mathrm{C}$-banding.

In a general analysis, AluI was the enzyme that produced the most divergent effects on the $\mathrm{CH}$ of Peromyscus eremicus chromosomes. In some cases, such as in chromosomes PER1 and PER6, some C-bands seem to have undergone a greater reduction or even have, apparently disap- 
peared when compared with control experiment, while in other cases, such as chromosomes PER7 and PER16, the $\mathrm{CH}$ was apparently unaffected by treatment with this enzyme.

The $\mathrm{p}$ arms $\mathrm{CH}$ of PER2, PER3 and PER4 chromosomes are particularly interesting in what respects to its molecular nature. In these heterochromatic arms the $\mathrm{CH}$ reveals a high heterogeneity, what is verified by the different restriction patterns produced by the enzymes at these $\mathrm{CH}$ regions. For instance in the $\mathrm{p}$ arm of PER 2 there were recognized two C-bands in the control $\mathrm{G}+\mathrm{C}$-banding; after $\mathrm{AluI}+\mathrm{C}$ restriction a lesser intensity of one of these bands was observed and ApaI + C-banding and HaeIII + C-banding seem to reveal an extra C-band, by splitting one of the previous in two [bands evidenced with an asterisk (*) in Figure 2].

\section{Constitutive heterochromatin (C-positive heterochromatin) characterization in Praomys tullbergi}

From the studied species, Praomys tullbergi (Figure 3 ) is the one whose chromosomes exhibit the lower amount of centromeric $\mathrm{CH}$ in the control experiment $(\mathrm{G}+\mathrm{C}$ banding). In some chromosomes, centromeric $\mathrm{CH}$ is almost as abundant as interstitial $\mathrm{CH}$, in contrast to the observed for the majority of the chromosomes from the other species here analyzed. However, the chromosomes PTU5 and PTU10 in the control experiment, present a small centromeric $\mathrm{CH}$ band and apparently do not reveal interstitial bands. The majority of the chromosomes display several interstitial $\mathrm{CH}$ bands, presenting the chromosomes PTU1 and PTU2 the greatest number of these bands. Telomeric $\mathrm{C}$-bands are clearly distinguishable in some chromosomes, e.g., chromosomes PTU10, PTU12 and PTU15. The PTUX chromosome presents three distinct classes of $\mathrm{CH}$, centromeric, interstitial and telomeric. PTUY chromosome exhibits a centromeric band and two interstitial C-bands.

When C-banding was applied after in situ REs digestion to the chromosomes of this species, it was possible to verify that its $\mathrm{CH}$ shows some degrees of heterogeneity, just as it was described for the other two rodent species studied in this work. AluI+C-banding produced the higher contrast between the centromeric versus interstitial/telomeric $\mathrm{CH}$ classes; digestion with AluI greatly decreased the interstitial/telomeric $\mathrm{CH}$ while, simultaneously, evidenced the centromeric heterochromatin. See for instance, chromosomes PTU15 or PTU16, whose centromeres showed in the control $\mathrm{G}+\mathrm{C}$-banding an almost absence of $\mathrm{CH}$, and after the AluI+C-banding the centromeres showed large centromeric $\mathrm{CH}$ blocks. Digestion with DraI seems to highlight the telomeric $\mathrm{CH}$ after $\mathrm{C}$-banding, e.g., chromosomes PTU7 and PTU16. RsaI+C-banding seems to produce the most similar results with the control $\mathrm{G}+\mathrm{C}$-banding, however also discriminating cryptic C-bands, such as the ones observed in chromosomes PTU4, PTU5, PTU10 or PTUX.
Other endonucleases also disclosed cryptic C-bands, especially DraI $+\mathrm{C}$-banding, BamHI $+\mathrm{C}$-banding or HaeIII $+\mathrm{C}$ banding.

These special bands are very interesting from the $\mathrm{CH}$ molecular nature point of view, since their disclosure is probably dependent on sequence modifications (not yet clearly understood) induced by the REs, leading for instance, to an increase of the stain capacity to bind a specific chromosome region (Gosálvez et al., 1997; Nieddu et al., 1999; Chaves et al., 2004b). Whatever the mechanism behind these sequences modification, RE digestion triggers it, revealing "hidden" C-bands. Curiously, and from several different works in different species, these sequences not detected by classical C-banding have proven to correspond to clinical (Sus scrofa, Adega et al., 2005) or evolutionary breakpoints (Tayassuidae, Adega et al., 2007).

\section{Inter-species constitutive heterochromatin (C-positive heterochromatin)}

A general comparison of the amount, distribution and molecular nature of C-positive heterochromatin in the three Rodentia species, suggests that the $\mathrm{CH}$ of these karyotypes is extremely different. Evidence comes from the detailed combined analysis of the different $\mathrm{REs}+\mathrm{C}$-banding patterns disclosed on the karyotypes of these species. The application of a seven REs panel to the chromosomes of three different rodent species, Cricetus cricetus, Peromyscus eremicus (Cricetidae) and Praomys tullbergi (Muridae), allowed a characterization of its $\mathrm{CH}$ and the recognition of its molecular heterogeneity. These results are a clear reflex of the different C-positive heterochromatin composition of these karyotypes, possible to observe by the different REs actions on the respective chromosome's bands.

Cricetus cricetus has an almost entirely meta/submetacentric karyotype (with only one acrocentric pair), with the $\mathrm{CH}$ primarily located in (peri)centromeric regions. Most of the chromosomes in this species exhibit two very large blocks at (peri)centromeric location, which suggested the occurrence of dicentric Robertsonian translocations or, alternatively, heterochromatin additions during the course of this karyotype evolution. The other Cricetidae species, Peromyscus eremicus, has a very distinct karyotype that comprises only submetacentric chromosomes. This karyotype also displays great amounts of $\mathrm{CH}$, especially located at the (peri)centromeric regions, being the $\mathrm{p}$ arms of some chromosomes composed entirely by this repetitive component of the genome. The heterochromatin of $\mathrm{p}$ arms revealed a great heterogeneity, what implies a different molecular composition, which is certainly indicative of the coexistence of different satellite DNA families or variants at these chromosome regions.

The species Praomys tullbergi, with a complete acrocentric autosome complement, it is the one whose chromosomes exhibit the lower amount of centromeric $\mathrm{CH}$ in the control experiment ( $\mathrm{G}+\mathrm{C}$-banding), and in some cases, in- 


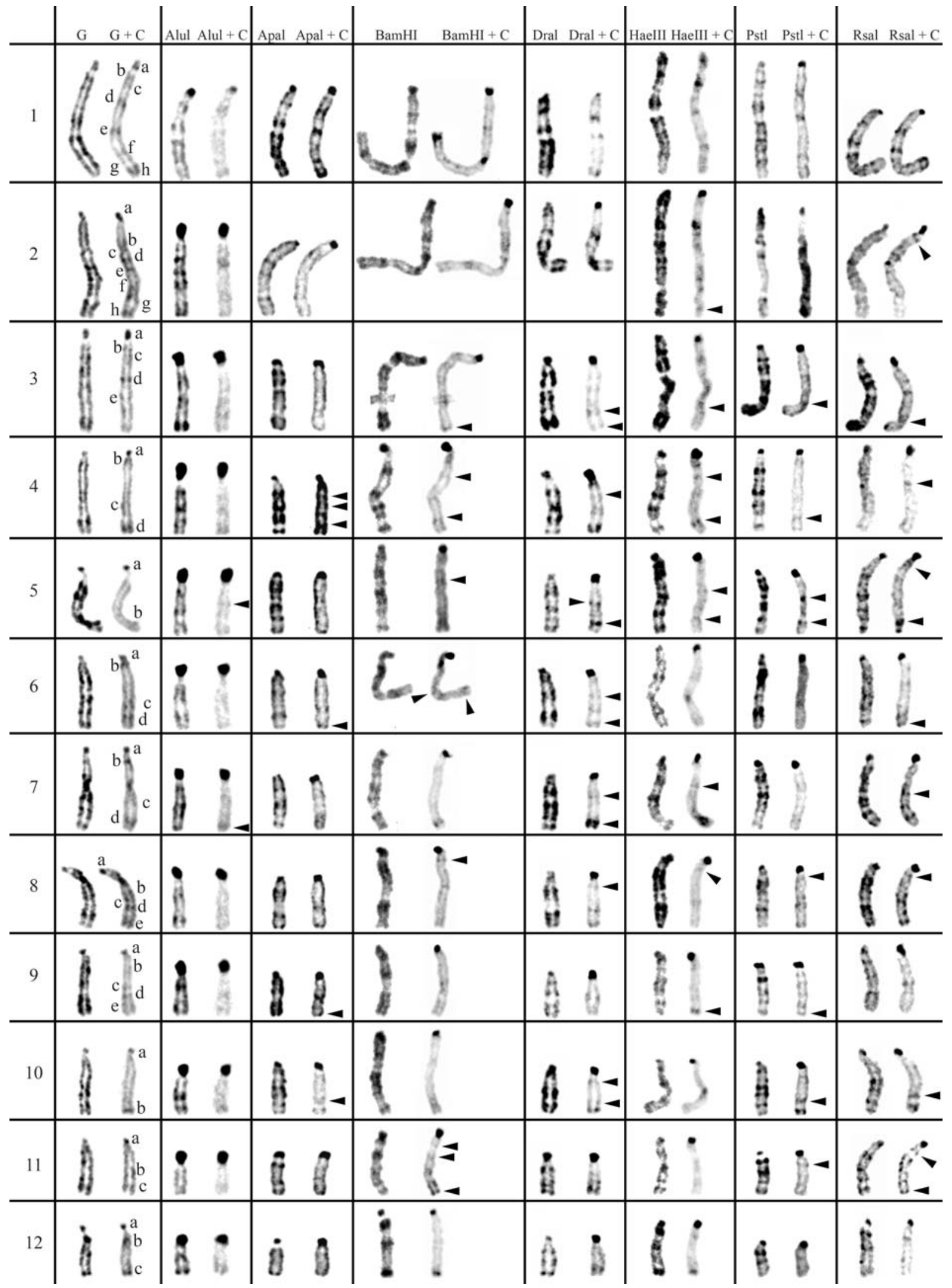

Figure 3 - Table resume of in situ restriction endonuclease digestion of Praomys tullbergi chromosomes $(2 \mathrm{n}=34)$ and sequential C-banding. Control Gand C-banding of Praomys tullbergi chromosomes are shown on the left column. The other columns show the bands produced by the seven different restriction endonucleases, before and after C-banding. The letters (a-h) represent the C-bands according to their order of appearance in each chromosome. Arrowheads indicate $\mathrm{C}$-positive heterochromatin bands only revealed by previous RE treatment. 


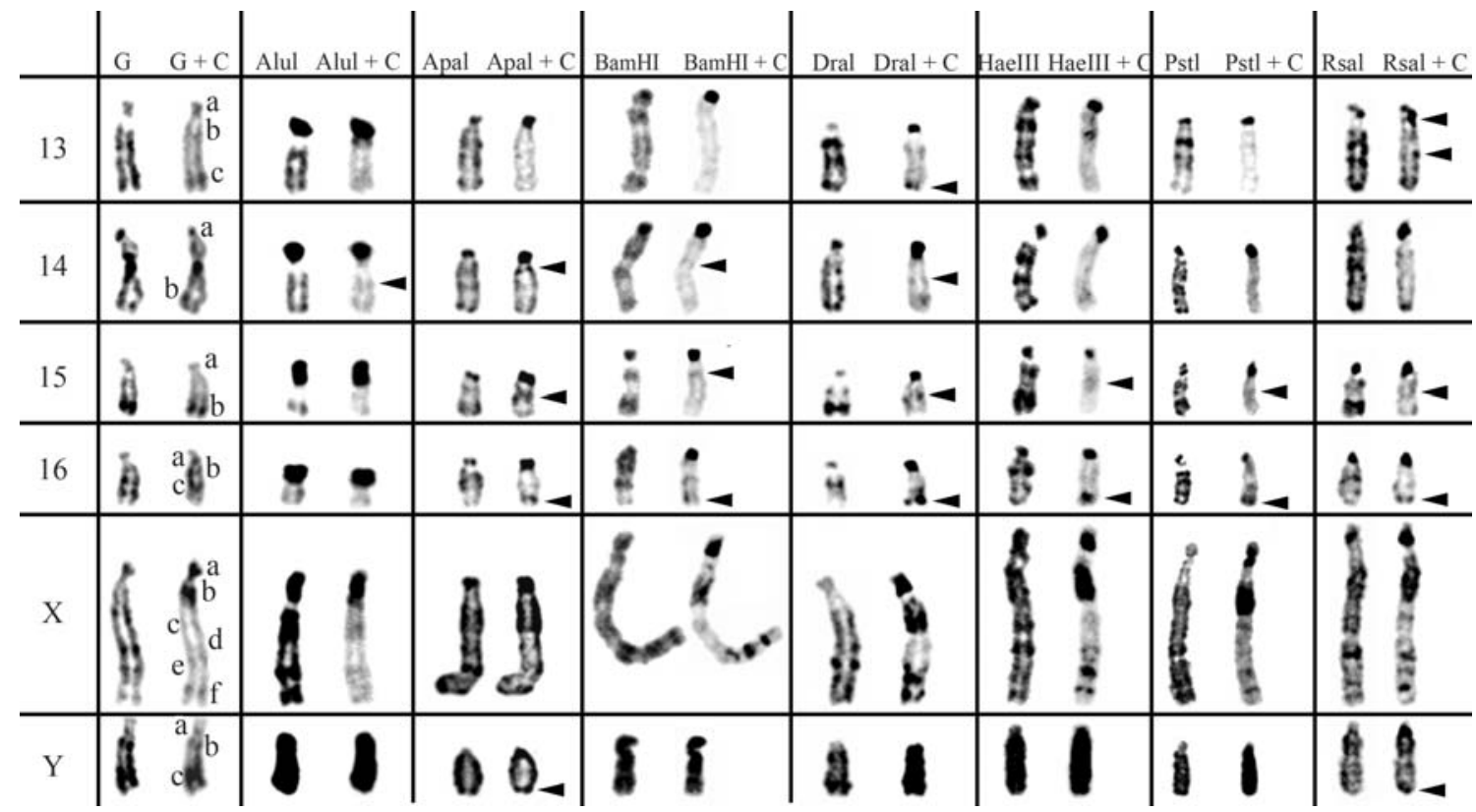

Figure 3 (cont.) - Table resume of in situ restriction endonuclease digestion of Praomys tullbergi chromosomes $(2 \mathrm{n}=34)$ and sequential C-banding. Control G- and C-banding of Praomys tullbergi chromosomes are shown on the left column. The other columns show the bands produced by the seven different restriction endonucleases, before and after C-banding. The letters (a-h) represent the C-bands according to their order of appearance in each chromosome. Arrowheads indicate C-positive heterochromatin bands only revealed by previous RE treatment.

terstitial heterochromatin is almost as abundant as centromeric heterochromatin. This uniform and scattered distribution, together with the higher number of $\mathrm{CH}$ subclasses identified in Praomys tullbergi chromosomes (52 subclasses) suggests that this species has a more derivative karyotype than the other two genomes analyzed, probably originated by a great number of complex chromosomal rearrangements. This is based on the assumption that heterochromatic rich regions act as hotspots for the occurrence of chromosome rearrangements (Yunis and Yasmineh, 1971; Peacock et al., 1982, John, 1988; Chaves et al., 2004b), either by promoting the chromosome structural rearrangements that reshape karyotypes or by being fragile regions prone to chromosome breakage, and consequently to chromosome rearrangement, representing remnants of these events. The suggestion that the karyotype of Praomys tullbergi was originated by the occurrence of a high number of complex chromosomal rearrangements is supported by the work of Meles et al. (2008), where it was detected telomeric interstitial sequences in several chromosome arms of this species, probably the result of tandem fusions.

Finally, it is worth mentioning the value of in situ RE digestion with sequential C-banding as an alternative tool for the study of Rodentia chromosomes $\mathrm{CH}$, especially when other techniques are not available, as fluorescent in situ hybridization with different repetitive sequences.

\section{Acknowledgments}

This work was supported by a project (POCI/BIA$\mathrm{BCM} / 58541 / 2004$ ) and a $\mathrm{PhD}$ grant (SFRH/BD/ 41574/2007) from the Science and Technology Foundation (FCT), Portugal. We are deeply grateful Dr. Vitaly Volobouev for providing the cell cultures of the Rodentia species.

\section{References}

Adega F, Chaves R and Guedes-Pinto H (2005) Chromosome restriction enzyme digestion in domestic pig (Sus scrofa). Constitutive heterochromatin arrangement. Genes Genet Syst 80:49-56.

Adega F, Chaves R and Guedes-Pinto H (2007) Constitutive heterochromatin characterization of white-lipped and collared peccaries (Tayassuidae). J Genet 86:19-26.

Arrighi FE and Hsu TC (1971) Localization of heterochromatin in human chromosomes. Cytogenetics 10:81-86.

Babu A (1988) Heterogeneity of heterochromatin of human chromosomes as demonstrated by restriction endonuclease treatment. In: Verma RS (ed) Heterochromatin: Molecular and Structural Aspects. 1st edition. Cambridge University Press, New York, pp 250-275.

Bauchan GR and Hossain MA (1999) Constitutive heterochromatin DNA polymorphisms in diploid Medicago sativa ssp. falcata. Genome 42:930-935.

Capanna E, Codjia JTC, Chrysostome C and Civitelli MV (1996) Les chromosomes des rongeurs du Benin (Afrique de l'Ouest): 3 Murinae. Rend Fis Acc Lincei 8:25-37. 
Chaves R, Guedes-Pinto H, Heslop-Harrison J and Schwarzacher $T$ (2000) The species and chromosomal distribution of the centromeric alpha-satellite I sequence from sheep in the tribe Caprini and other Bovidae. Cytogenet Cell Genet 91:62-66.

Chaves R, Adega F, Santos S, Guedes-Pinto H and HeslopHarrinson JS (2002) In situ hybridization and chromosome banding in mammalian species. Cytogenet Genome Res 96:113-116.

Chaves R, Frönicke L, Guedes-Pinto H and Wienberg J (2004a) Multidirectional chromosome painting between the Hirola antelope (Damaliscus hunteri, Alcelaphini, Bovidae), sheep and human. Chromosome Res 12:495-503.

Chaves R, Santos S and Guedes-Pinto H (2004b) Comparative analysis (Hippotragini versus Caprini, Bovidae) of Xchromosome's constitutive heterochromatin by in situ restriction endonuclease digestion: X-chromosome constitutive heterochromatin evolution. Genetica 121:315-325.

Comings DE (1973) Biochemical mechanisms of chromosome banding and color banding with acridine orange. In: Casperson $\mathrm{T}$ and Zeck L (eds) Chromosome Identification Techniques and Applications in Biology and Medicine. Academic Press, New York, pp 292-306.

Corradini N, Rossi F, Giordano E, Caizzi R, Vern F and Dimitri P (2007) Drosophila melanogaster as a model for studying protein-encoding genes that are resident in constitutive heterochromatin. Heredity 98:3-12.

Dimitri P, Corradini N, Rossi F and Verní F (2004) The paradox of functional heterochromatin. BioEssays 27:28-41.

Dimitri P, Verní F, Mei E, Rossi F and Corradini N (2005) Transposable elements as artisans of the heterochromatic genome. Cytogenet Genome Res 110:165-172.

Fernández-García JL, Martínez-Trancón M, Rabasco A and Padilla JA (1998) Characterization of the heterochromatic chromosome regions in sheep. Genes Genet Syst 73:45-50.

Galleni L, Stanyon R, Tellini A, Giordano G and Santini L (1992) Karyology of the Savi pine vole, Microtus savii (De SélysLongchamps, 1838) (Rodentia, Arvicolidae): G-, C-, DA/DAPI, and AluI-bands. Cytogenet Cell Genet 59:290292.

García L, Ponsá M, Egozcue J and García M (2000a) Comparative chromosomal analysis and phylogeny in four Ctenomys species (Rodentia, Octodontidae). Biol J Linn Soc 69:103-120.

García L, Ponsá M, Egozcue J and García M (2000b) Cytogenetic variation in Ctenomys perrensi (Rodentia, Octodontidae). Biol J Linn Soc 71:615-624.

Gosálvez J, López-Fernández C, Goyanes R and Mezzanotte V (1997) Chromosome differentiation using nucleases: An overview. In: Henriques-Gil N, Parker JS and Puertas MJ (eds) Chromosomes Today. Chapman \& Hall, London, pp 23-49.

Holmquist GP and Dancis B (1979) Telomere replication, kinetochore organizers, and satellite DNA evolution. Proc Natl Acad Sci USA 76:4566-4570.

Hsu TC and Arrighi FE (1966) Chromosomal evolution in the genus Peromyscus (Cricetidae, Rodentia). Cytogenetics 5:355-359.

Jobse C, Buntjer JB, Haagsma N, Breukelman HJ, Beintema JJ and Lenstra JA (1995) Evolution and recombination of bovine DNA repeats. J Mol Evol 41:277-283.
John B (1988) The biology of heterochromatin. In: Verma RS (ed) Heterochromatin: Molecular and Structural Aspects. Cambridge University Press, Cambridge, pp 1-128.

John B, King M, Schweizer D and Mendelak M (1985) Equilocality of heterochromatin distribution and heterochromatin heterogeneity in acridid grasshoppers. Chromosoma 91:185-200.

Lee C, Stanyon R, Lin CC and Ferguson-Smith MA (1999) Conservation of human gamma-X centromeric satellite DNA among primates with an autosomal localization in certain Old World monkeys. Chromosome Res 7:43-47.

Matthey R (1952) Chromosomes des Muridae (Microtinae et Cricetinae). Chromosoma 5:113-138.

Matthey R (1958) Les chromosomes et la position systématique de quelques Murinae africains (Mammalia-Rodentia). Acta Trop 15:97-117.

Meles S, Adega F, Guedes-Pinto H and Chaves R (2008) The karyotype of Praomys tullbergi (Muridae, Rodentia): A detailed characterization. Micron 39:559-568.

Nieddu M, Rossino R, Pichiri G, Rocchi M, Setzu MD and Mezzanotte R (1999) The efficiency of in situ hybridization on human chromosomes with alphoid DNAs is enhanced by previous digestion with AluI and TaqI. Chromosome Res 7:593-602.

Pathak S and Arrighi FE (1973) Loss of DNA following Cbanding procedures. Cytogenet Cell Genet 12:414-422.

Peacock WJ, Dennis ES and Gerlach WL (1982) DNA sequence changes and speciation. Prog Clin Biol Res 96:123-142.

Pieczarka JC, Nagamachi CY, Muniz JAPC, Barros RMS and Mattevi MS (1998) Analysis of constitutive heterochromatin of Aotus (Cebidae, Primates) by restriction enzyme and fluorochrome bands. Chromosome Res 6:77-83.

Probst AV and Almouzni G (2008) Pericentric heterochromatin: Dynamic organization during early development in mammals. Differentiation 76:15-23.

Qumsiyeh MB, King SW, Arroyo-Cabrales J, Aggundey IR, Schlitter DA, Baker RJ and Morrow KJ (1990) Chromosomal and protein evolution in morphologically similar species of Praomys sensu lato (Rodentia, Muridae). J Hered 81:58-65.

Rocco L, Morescalchi MA, Costagliola D and Stingo V (2002) Karyotype and genome characterization in four cartilaginous fishes. Gene 295:289-298.

Rossi F, Moschetti R, Caizzi R, Corradini N and Dimitri P (2007) Cytogenetic and molecular characterization of heterochromatin gene models in Drosophila melanogaster. Genetics 175:595-607.

Saito Y, Edpalina RR and Abe S (2007) Isolation and characterization of salmonid telomeric and centromeric satellite DNA sequences. Genetica 131:157-166.

Santos S, Chaves R and Guedes-Pinto H (2004) Chromosomal localization of the major satellite DNA family (FA-SAT) in the domestic cat. Cytogenet Genome Res 107:119-122.

Schmid M, Haaf T, Steinlein C, Nanda I and Mahony M (2002) Chromosome banding in Amphibia: XXV. Karyotype evolution and heterochromatin characterization in Australian Mixophyes (Anura, Myobatrachidae). Cytogenet Genome Res 97:239-253.

Seabright M (1971) A rapid banding technique for human chromosomes. Lancet 2:971-972. 
Shore D (2001) Telomeric chromatin: Replicating and wrapping up chromosome ends. Curr Opin Genet Dev 11:189-198.

Singer MF (1982) Highly repeated sequences in mammalian genomes. Int Rev Cytol 76:67-112.

Slamovits CH and Rossi MS (2002) Satellite DNA: Agent of chromosomal evolution in mammals. A review. J Neotrop Mammal 9:297-308.

Sumner AT (1972) A simple technique for demonstrating centromeric heterochromatin. Exp Cell Res 75:304-306.

Van Den Bussche RA, Honeycutt RL and Baker RJ (1993) Restriction endonuclease digestion patterns of harvest mice (Reithrodontomys) chromosomes: A comparison to Gbands, C-bands, and in situ hybridization. Genetica 87:141149.

Verma RS and Babu A (1995) Human Chromosomes - Principles and Techniques. 2nd edition. McGraw-Hill, New York, 419 pp.
Waye JS and Willard HF (1989) Concerted evolution of alpha satellite DNA: Evidence for species specificity and a general lack of sequence conservation among alphoid sequences of higher primates. Chromosoma 98:273-279.

Wichman HA, Payne CT, Ryder OA, Hamilton MJ, Maltbie M and Baker RJ (1991) Genomic distribution of heterochromatic sequences in equids: Implications to rapid chromosomal evolution. J Hered 82:369-377.

Yunis JJ and Yasmineh WG (1971) Heterochromatin, satellite DNA, and cell function. Structural DNA of eukaryotes may support and protect genes and aid in speciation. Science 174:1200-1209.

Associate Editor: Yatiyo Yonenaga-Yassuda

License information: This is an open-access article distributed under the terms of the Creative Commons Attribution License, which permits unrestricted use, distribution, and reproduction in any medium, provided the original work is properly cited. 